\title{
DESCRIPTION OF HISTOPATHOLOGICAL FEMORAL FRACTURE HEALING WITH IMPLANTATION OF GEL NANO-BCP- COLLAGEN IN MALE RATS
}

\author{
Yudith Violetta Pamulang'), Mellya Permatasari'1), Vigha Ilmanafi Arifka ${ }^{2)}$ \\ Josi Aldo Emmanuel Pramono3) Setyo Budhi') \\ 1)Faculty of Veterinary Medicine, Universitas Gadjah Mada, Yogyakarta \\ 2) Faculty of Pharmacy, Universitas Gadjah Mada, Yogyakarta \\ 3)Faculty of Engineering, Universitas Gadjah Mada, Yogyakarta
}

\begin{abstract}
Background: Approximately 1.3 million people were suffers from musculoskeletal fractures every year due to traffic accidents in the world. The process of fracture healing takes a long time so an implant material is needed to accelerate healing process. One such material is Biphasic Calcium Phosphate (BCP) which is a combination of hydroxiapatite (HA) and $\beta$-tricalcium phosphate ( $\beta$-TCP). The BCP has a balance between the time of decay and regeneration of bone tissue. This study aimed to describe and compare the histopathological femoral fracture healing process with and without implantation of gel Nano-BCP-collagen in male rats.

Subjects and Method: Synthesis of HA and $\beta$-TCP is done by the processes of (1) Calcination; (2) Precipitation, (3) Sintering; and (4) Synthesis of BCP with the sonication method. An analysis with X-Ray Diffraction Spectrometry (XRD) was carried out to characterize and evaluate the size of BCP crystallites. Gel preparations were made in two formulas: (1) Formula 1 (3.5\% collagen) and (2) Formula 2 (2\% collagen). These formulas were implanted in treatment groups 1 and 2, and then tested in vivo in male Wistar Rats in the presence of control + and control groups.

Results: XRD test results showed the formation of BCP crystals in the forms of $59.3 \%$ $\mathrm{HA}$ and $40.7 \% \beta$-TCP with a crystal size of $6.25 \mathrm{~nm}$. After the implantation of Gel Nano-BCP-Collagen, treatment groups 1 and 2 showed better histopathological healing process of the femoral fracture. Callus was formed to bridge the fracture perfectly. In the treatment groups 1 and 2, the callus formation was dominated by woven bone and trabecular bone. In the control group, the callus formation was dominated by fibrous connective tissue and cartilage.
\end{abstract}

Conclusion: Implantation of Gel Nano-BCP-Collagen is effective to accelerate the histopathological healing process of the femoral fracture.

Keywords: Fracture, Histopathology, Implantation, BCP, Collagen.

\section{Correspondence:}

Yudith Violetta Pamulang. Faculty of Veterinary Medicine, Universitas Gadjah Mada, Yogyakarta. Email: yudith.v@mail.ugm.ac.id. Mobile: 085700041094. 